Revista Educação e Políticas em Debate - v. 7, n. 2, p. 263 -288, mai./ago. 2018 - ISSN 2238-8346

\title{
O financiamento da Educação Infantil após 30 anos da Constituição Federal 1988: avanços, contradições e desafios
}

\author{
The financing of Children Education after 30 years of the Federal Constitution 1988: \\ advances, contradictions and challenges
Le financement de l'éducation des Enfants après 30 ans de la Constitution Fédérale 1988: avancées, contradictions et défis

Joedson Brito dos Santos ${ }^{1}$ Universidade Federal do Tocantins

Luiz de Sousa Junior ${ }^{2}$ Universidade Federal da Paraíba

Resumo: O texto discute sobre o financiamento da educação infantil após 30 anos da Constituição Federal (CF) de 1988, considerando possíveis avanços, contradições e desafios. Trata-se de uma pesquisa teórica com análise documental. Parte-se do pressuposto de que, para garantir o direito à educação infantil, não basta a criação de dispositivos legais, é imprescindível criar mecanismo de financiamento. O estudo analisa, a partir dos marcos constitucionais, como a educação infantil vai se configurando como etapa educativa e política educacional e qual seu lugar na política de financiamento. Apesar dos avanços promovidos nesses 30 anos da $\mathrm{CF} / 88$, o financiamento da educação infantil segue envolto numa contradição entre a garantia do direito e ausência de prioridade legal. É necessário superar a focalização da aplicação dos recursos no ensino fundamental e ampliar os recursos para a educação infantil.

Palavras-Chave: Financiamento da Educação Infantil. Direito à educação. Contradições.

Abstract: The text discusses the financing of children's education after 30 years of the 1988 Federal Constitution (CF), considering possible advances, contradictions and challenges. This is a theoretical research with documentary analysis. It is assumed that, in order to guarantee the right to early childhood education, it is not enough to create legal provisions, it is essential to create a financing mechanism. The study analyzes, from the constitutional milestones, how the education of children is becoming an educational stage and educational policy and its place in the financing policy. Despite the advances made during these 30 years of $\mathrm{CF} / 88$, the financing of early childhood education is still involved in a contradiction between the guarantee of the right and lack of legal priority. It is necessary to overcome the focus on the application of resources in primary education and to increase the resources for early childhood education.

\footnotetext{
${ }^{1}$ Doutor em Educação pela Universidade Federal da Paraíba (UFPB). Professor Adjunto da Universidade Federal do Tocantins (UFT), líder do Grupo de Estudos e Pesquisas em Política e Prática Educativa (Gepppe) e membro do Núcleo de Estudos e Pesquisa em Educação, Desigualdade Social e Políticas Públicas (Neped). E-mail: jbsantus@uf.edu.br

${ }^{2}$ Doutor em Educação pela Universidade São Paulo (USP). Professor Associado da Universidade Federal da Paraíba (UFPB), vinculado ao PPGE/CE/UFPB. Atualmente, é coordenador de programas profissionais da área de Educação da CAPES. Professor da Universidade Federal da Paraíba (UFPB). E-mail: luizsjunior@gmail.com
} 
Key words: Financing of child education. Right to education. Contraditions.

Le texte traite du financement de l'éducation des enfants après 30 ans de la Constitution fédérale de 1988, en considérant les progrès, les contradictions et les défis possibles. C'est une recherche théorique avec analyse documentaire. Il est supposé que, pour garantir le droit à l'éducation de la petite enfance, il ne suffit pas de créer des dispositions légales, il est essentiel de créer un mécanisme de financement. L'étude analyse, à partir des jalons constitutionnels, comment l'éducation des enfants devient une étape éducative et une politique éducative et sa place dans la politique de financement. Malgré les progrès réalisés au cours de ces 30 années de $\mathrm{CF} / 88$, le financement de l'éducation de la petite enfance est toujours impliqué dans une contradiction entre la garantie du droit et le manque de priorité juridique. Il est nécessaire de surmonter l'accent mis sur l'utilisation des ressources dans l'éducation primaire et d'augmenter les ressources pour l'éducation de la petite enfance.

Mots clés: Financement de l'éducation de la petite enfance. Droit à l'éducation Contradictions

Recebido em: 01 de setembro de 2018 Aceito em: 25 de outubro de 2018

\section{Introdução}

O marco da mudança na história do atendimento à infância no Brasil foi a promulgação da Constituição Federal (CF) de 1988 que incluiu a educação infantil (EI) no Capítulo da Educação e reconheceu essa área como um direito subjetivo do ser humano, como um dos deveres do Estado e a criança como um sujeito de direito, fato que suplanta a natureza educacional desse atendimento em detrimento do assistencial. As mudanças promovidas pela Constituição de 1988 influenciaram, expressivamente, os rumos desse segmento e culminaram na inclusão da EI como a primeira etapa da Educação Básica na Nova Lei de Diretrizes e Bases da Educação Nacional (LDB) instituída pela Lei nº 9.394 em dezembro de 1996.

Todavia, apesar da Constituição Federal de 1988, do Estatuto da Criança e do Adolescente (Lei nº 8.069 de 1990), da Lei de Diretrizes e Bases da Educação Brasileira (Lei $n^{\circ}$ 9.394 de 1996), e de tantos outros dispositivos legais, criados nos últimos 20 anos, dispondo sobre a educação infantil como direito das crianças de 0 a 5 anos de idade e sobre as especificidades desse atendimento, o direito à educação para a primeira infância ainda não está assegurado, nem universalizado. Considerem-se os baixos percentuais de atendimento de crianças de 0 a 5 anos de idade em creches e pré-escolas, principalmente, quando se trata do segmento de 0 a 3 anos, imensa demanda por vagas; e as condições precárias de ofertas dos serviços, tanto em relação à qualificação docente, quanto em relação à infraestrutura físicas e 
pedagógicas das instituições, e aos processos de desigualdades educacionais no atendimento ${ }^{3}$. Nesse sentido, é importante incrementar os debates sobre a ampliação da "cobertura, a formação das professoras, condições de infraestrutura, proporção adulto-criação, organização dos espaços" (DIAS; MACÊDO, 2011, p. 179) e, sobretudo, a expansão dos recursos para o financiamento dessa etapa da educação.

Tais aspectos nos fazem concordar com Bobbio (1992), ao defender que a garantia do direito não se resume ao fato deste estar inscrito em lei ou constituições, mas nos mecanismos de proteção e de financiamento para que esse direito seja assegurado. A garantia do direito à educação infantil não se faz apenas mediante a criação de dispositivos legais e jurídicos, mas diante da criação de política pública social que assegure recursos financeiros para sua operacionalização (CURY, 2007), bem como de mecanismos de proteção e fiscalização desses recursos.

Essa constatação se confirma ao verificarmos que, até final de 2006, não existia uma política que definisse claramente a noção de recursos para o financiamento do atendimento das crianças de 0 a 6 anos de idade. O Fundo de Manutenção de Desenvolvimento do Ensino Fundamental e de Valorização dos Profissionais do Magistério (Fundef), política de financiamento no âmbito da educação básica, aprovada em dezembro de 1996, mesmo mês e ano em que esse segmento foi elevado à primeira Etapa da Educação Básica com a promulgação da LDB de 1996, priorizou o financiamento do ensino fundamental em detrimento de outros segmentos da educação básica, dentre eles a educação infantil (PINTO 2006; SOUZA Jr 2006).

Somente com a criação do Fundo de Manutenção e Desenvolvimento da Educação Básica e de Valorização dos Profissionais da Educação (Fundeb), regulamentado no final de 2006 e início de 2007, que a educação infantil passou a ser pensada dentro de uma política de financiamento público para a educação e a receber recursos desse Fundo mediante cada nova matrícula nesse segmento. Tal fato representa um momento histórico para o atendimento das crianças de 0 a 6 anos de idade, principalmente a de 0 a 3 anos que, tradicionalmente, eram consideradas uma responsabilidade de natureza privada no âmbito da família e não do Estado. Dessa forma, esse público, na área da educação, passou a receber recursos constitucionalmente vinculados (ROSEMBERG, 2010). No entanto, para alguns desses mesmos pesquisadores, é preciso ter muita cautela ao estudar o financiamento da EI no Fundeb (DIDONET, 2006; ROSEMBERG, 2010).

\footnotetext{
${ }^{3}$ Ver (CAMPOS, 2006; 2010)
} 
Assim, o presente texto tem como objetivo discutir sobre o financiamento da educação infantil após Constituição Federal de 1988, considerando os avanços e desafios. Além disso, este estudo apresenta elementos estruturais e conjunturais da configuração da educação infantil e de seu financiamento após CF de 1988; o Fundeb enquanto atual política de financiamento da educação básica brasileira, e seu reflexo no provimento da educação de crianças de $\mathrm{O}$ a 6 anos de idade; e, por fim alguns avanços e desafios posto para esse segmento a partir da implementação desse fundo. O texto, dessa forma, procura situar a importância da problemática e convida o leitor para um olhar mais atento sobre esse tema.

Constituição Federal 1988 e a garantia do direito à educação infantil: quando não basta a criação de dispositivos legais

A Constituição de 1988 representa um grande salto para a criança de o a 6 anos, assegurando seus direitos e, entre esses, o direito à educação infantil. No artigo $7^{\circ}$, inciso XXV, o documento inclui a " $[\ldots]$ assistência gratuita aos filhos e dependentes desde o nascimento até seis anos de idade em creches e pré-escolas [...]”; No art. 205, a Constituição define a educação como direito de todos. No artigo 208, a mesma lei garante a efetivação do dever do Estado com a educação, e inclui no inciso IV, o atendimento em creches e pré-escolas às crianças de $\mathrm{O}$ a 6 anos. $\mathrm{O}$ documento atribui responsabilidade ao município no artigo 30, inciso I, sobre a cooperação técnica e financeira juntamente com a União e o Estado para manter programas de educação infantil e de ensino fundamental (redação alterada pela EC/53, pois, antes, falava em pré-escola e de ensino fundamental). Aspecto reafirmado, no art. 211, que dispõe que os municípios devem organizar seus sistemas de ensino em Regime de colaboração com União e Estado e, no $£ 1^{\circ}$, que a União deve manter função supletiva e redistributiva em todos os níveis, mediante assistência técnica e financeira. Esses aspectos reforçam que a educação infantil deveria ser uma prioridade dos municípios, mas que, para ser assegurado, deveria receber apoio, cooperação e assistência tanto técnica quando financeira. Além disso, o artigo 212 da CF/88 definiu que a educação infantil deveria ser mantida e financiada com os recursos vinculados à Manutenção e Desenvolvimento do Ensino (MDE).

Após a CF 1988, surgem inúmeros documentos e leis no sentido de garantir, sistematizar e consolidar o direito dos infantes à educação. Por exemplo, foi instituído pela Lei n 8.069 de 1990, o Estatuto da Criança e do Adolescente (ECA), foi elaborada e aprovada a "Política Nacional da Educação Infantil: pelo direito das crianças de zero a seis anos de idade”, 
o documento "Por uma Política de Formação do Profissional da Educação Infantil", o Referencial Curricular Nacional para a Educação Infantil (RCNEI), as Diretrizes Curriculares Nacionais para a Educação Infantil (DCNEI) e a Lei nº 10.172 que criou o PNE de 2001 e estabeleceu 25 metas para essa etapa educativa. Esses ordenamentos normativos e políticos, de certa forma, evidenciaram uma nova fase do atendimento à criança pequena no Brasil, que exigiu maior direcionamento de seu caráter educacional e políticas públicas no sentido de assegurar seu provimento enquanto um direito.

Na década de 1990, entre os principais ordenamentos normativos estiveram o Estatuto da Criança e do Adolescente (ECA) e a Lei de Diretrizes e Bases da Educação Brasileira (LDB) (Lei $n^{\circ}$ 9.394/96) que instituiu a LDB reconheceu e elevou a educação infantil como primeira etapa da educação básica dedicando a ela um capítulo específico. Essa lei, afirmação da natureza educacional desse processo, exigiu novas estruturas e infraestrutura, bem como definição de um currículo e de um perfil profissional específico para esse segmento. Essa lei definiu sobre estrutura, funcionamento, responsabilidades e formação de profissionais da educação básica; e dispôs que as instituições de educação infantil deveriam ser integradas aos Sistemas Municipais de Ensino.

No título IX, Das Disposições Transitórias, art. 89: a LDB destaca: “As creches e préescolas existentes ou que venham a ser criadas deverão, no prazo de três anos, a contar da publicação desta Lei, integrar-se ao respectivo sistema de ensino". E no título IV, art. 11, V: “Os Municípios incumbir-se-ão de:

[...] oferecer a educação infantil em creches e pré-escolas, e, com prioridade, o ensino fundamental, permitida a atuação em outros níveis de ensino quando estiverem atendidas plenamente as necessidades de sua área de competência e com recursos acima dos percentuais mínimos vinculados pela Constituição Federal à manutenção e desenvolvimento do ensino".

Essas disposições representaram elementos positivos, do ponto de vista de induzir e pressionar o poder público municipal a assumir a responsabilidade pelo provimento e oferta de vagas dessa etapa da Educação (MACÊDO; DIAS, 2011). Todavia, a municipalização da educação infantil -em consonância com a CF/88 em seu artigo 30, inciso VI, e com o artigo 211, parágrafo $2^{\circ}$ (Redação dada pela $\mathrm{EC}^{\circ}{ }^{\circ} 14$ de 1996)- que determinou que os Municípios atuariam prioritariamente no ensino fundamental e na educação infantil não foi acompanhada de recursos suficientes para possibilitar aos entes municipais desenvolver ações com a qualidade, ampliar suas redes de ensino e oferta de vagas para esse segmento, investir na 
formação de professores e demais profissionais que atuavam nessa, então, nova etapa da educação básica, bem como melhorar as condições precárias de infraestrutura.

Instituído pela Emenda Constitucional EC no 14, de setembro de 1996, o Fundef alterou o art. 60 do ADCT da CF de 1988, foi regulamentado pela Lei $n^{\circ}$ 9.424, de 24 de dezembro de 1996, e pelo Decreto $\mathrm{n}^{\circ}$ 2.264, de 1997, focalizou atenção e recursos, prioritariamente no ensino fundamental, o que ocasionou limitação aos municípios em cumprir as disposições legais, pois passou a subvincular, para o ensino fundamental, $15 \% \operatorname{dos} 25 \%$ dos recursos de estados e municípios já vinculados à Manutenção e Desenvolvimento do Ensino, nos termos dispostos no art. 212 da CF/88. Desses 15\%, no mínimo 60\% deveriam ser aplicado na valorização dos profissionais do magistério em exercício.

Em geral, muitos municípios se sentiram sobrecarregados com poucos recursos financeiros e humanos para expandir a oferta da educação infantil, pois isso implicava na ampliação de quadro de professores, aumento de número de escolas, de salas e de espaços adequados; e na elaboração de padrões mínimos de qualidade, formação de profissionais, alimentação, além de material adequado. Esses aspectos também foram definidos entre as 25 metas indicadas no PNE de 2001 para a EI.

Ao fazer esse recorte preferencial, o Fundef acabou por causar um retrocesso na compreensão e no conceito de educação básica, focalizando o atendimento apenas no ensino fundamental, o que explicita uma contradição da defesa da garantia do direito à EI. Esse fato impactou negativamente as políticas de financiamento educativo da EI, bem como de outras etapas e modalidades da educação básica, como a educação de jovens e adultos (EJA). Esse fato acabou legitimando e fortalecendo as desigualdades educacionais e sociais já existentes entre os segmentos da educação brasileira.

Nesse contexto, as discussões sobre o Financiamento da Educação, da Educação Básica e, com intensidade, da Infantil começam a ganhar maior espaço no Brasil. A promulgação da Lei n ${ }^{\circ}$ 9.394/96, que definiu EI como primeira etapa da educação básica, o direcionamento para sua inclusão nos sistemas municipais de ensino, a criação do Fundef, e a definição de metas e prioridades no PNE/2001 trouxeram elementos para o aumento das reflexões, debates e discussões sobre a necessidade de recursos para a financiamento da EI, bem como sobre os limites de estados e municípios em assegurarem o direito à educação e a valorização dos profissionais do magistério em geral. Atrelado a esses aspectos sobre a focalização do financiamento no ensino fundamental e a ausência de recursos para assegurar o PNE/2001, 
tornou-se imprescindível o debate sobre a urgência de recursos para o financiamento de toda educação básica, incluindo a educação infantil.

Viu-se surgir e outras propostas de política de financiamento da educação básica, algumas dessas tinham como objetivo a reformulação ou o aperfeiçoamento do Fundef com inclusão da educação infantil ou com o direcionamento dos 10\% da receita do MDE que restava depois que retirava os 15\% do Fundef, , para a educação infantil, por exemplo. Destacaram-se também algumas propostas diretamente ligadas ao financiamento dessa etapa da Educação, como a criação de três fundos: um para educação infantil, uma para o ensino médio e o Fundef; a criação de dois fundos: um para a creche e outro para a pré-escola; e a criação de um fundo para toda EB (ABREU, 2004; DIDONET, 2006).

Na verdade, a noção de gratuidade, de igualdade e de direito à educação subsidia, historicamente, o conceito de educação pública que traz, de forma inerente, a defesa da responsabilidade do estado em assegurá-la, seja em sua organicidade, seja no que se refere aos seus custos. Por isso, quando um país faz a opção em oferecer, ampliar ou universalizar o acesso e a obrigatoriedade à educação escolar pública, para sua população ou para parte dela, cumpre a ele estabelecer os mecanismos e as formas de financiamento.

Constituição Federal 1988 e a garantia do direito à educação: cumpre estabelecer os mecanismos e as formas de financiamento

A educação aparece como direito de todos e como dever do Estado em vários artigos, mais particularmente nos 205, 206 e 208. O artigo 205 dispõe, por exemplo, que a educação é um dever do Estado e da família e que será promovida por meio da participação da sociedade civil tendo como objetivo o pleno desenvolvimento da pessoa. O inciso IV, do artigo 208, além de fazer um detalhamento do direito à educação, destaca, especificamente, que o Dever do Estado com a Educação será efetivado mediante garantia de alguns princípios e condições, dentre alguns princípios, podemos citar os que têm relação direta com o financiamento da educação, como os de "gratuidade do ensino público em estabelecimentos oficiais" no parágrafo IV; a “valorização dos profissionais da educação escolar, garantidos, na forma da lei, planos de carreira, com ingresso exclusivamente por concurso público de provas e títulos, aos das redes públicas” (Redação dada pela Emenda Constitucional nº 53, de 2006) no parágrafo V; a "garantia de padrão de qualidade" no VII; e a definição de "piso salarial profissional nacional 
para os profissionais da educação escolar pública, nos termos de lei federal” no VIII (Incluído pela Emenda Constitucional $n^{\circ} 53$, de 2006).

Já dentre algumas das conduções, o Estado deve assegurar o direito à educação mediante a;

\footnotetext{
I - educação básica obrigatória e gratuita dos 4 (quatro) aos 17 (dezessete) anos de idade, assegurada inclusive sua oferta gratuita para todos os que a ela não tiveram acesso na idade própria; (Redação dada pela Emenda Constitucional $\mathrm{n}^{\circ}$ 59, de 2009) (Vide Emenda Constitucional n ${ }^{\circ}$ 59, de 2009)

II - progressiva universalização do ensino médio gratuito.

III - atendimento educacional especializado aos portadores de deficiência, preferencialmente na rede regular de ensino;

IV - educação infantil, em creche e pré-escola, às crianças até 5 (cinco) anos de idade.

VII - atendimento ao educando, em todas as etapas da educação básica, por meio de programas suplementares de material didático escolar, transporte, alimentação e assistência à saúde (BRASIL, 1988).
}

Essas condições postas no art. 208 da CF/88 não têm materialização ou operacionalidade sem recursos públicos financeiros suficientes e adequados. Por essa razão, a CF/88 sofreu alterações nos artigos que tratam do tema, após sua promulgação, por exemplo, a redação foi alterada pelas emendas constitucionais EC 14/96 e 53/06 que criaram respectivamente o Fundef e o Fundeb.

Universalizar a educação básica significa colocar milhões de crianças na escola - da pré-escola ao ensino médio (Redação dada pela Emenda Constitucional n 59, de 2009) - via matrícula, o que por si só já elevaria o quantitativo de recursos, per capita, haja vista tanto a vinculação do Fundeb quanto a distribuição de recursos via FNDE se operacionalizam mediante número de alunos. Contudo esse processo requer ampliação e aperfeiçoamento nas condições de infraestrutura, bem como a construção de novos espaços. Demanda-se ainda elevação do quadro de recursos humanos com qualificação e remuneração adequados. Tudo isso requer maior comprometimento da União e reestruturação do Pacto Federativo. Requer também controle social qualificado, técnico e especializado do uso dos recursos públicos da educação, controle e sanção legal ao não cumprimento, ou mau uso dos recursos educacionais.

A responsabilidade em assegurar as condições necessárias do direito à educação está dividida entre União, Estados, Distrito Federal e Municípios (arts. 211, 212 e 214). No art. 212, nos incisos I, III, IV, V e VI, no $\$ 1^{\circ}$, determina-se que "a parcela da arrecadação de impostos transferida pela União aos Estados, ao Distrito Federal e aos Municípios, ou pelos Estados aos respectivos Municípios” não pode ser considerada para efeito do cálculo dos percentuais previsto nesse artigo. $\mathrm{O} \$ 3^{\circ}$ institui que "a distribuição dos recursos públicos 
assegurará prioridade” na universalização, no padrão de qualidade e equidade, para o ensino obrigatório, com base no plano nacional de educação (Redação dada pela Emenda Constitucional $\mathrm{n}^{\circ} 59$, de 2009). O $\$ 4^{\circ}$ dispõe sobre a abrangência dos "programas suplementares de alimentação e assistência à saúde”, previstos no art. 208, VII, que serão financiados com recursos provenientes de contribuições sociais e outros recursos, que deverão incidir sobre toda educação obrigatória. No $\$ 5^{\circ}$, determina-se que a educação básica pública terá como fonte adicional de financiamento a contribuição social do salário-educação, recolhida pelas empresas na forma da lei (Redação dada pela Emenda Constitucional $n^{\circ}$ 53, de 2006) (Vide Decreto $n^{\circ}$ 6.003, de 2006). Já no $\$ 6^{\circ}$, as cotas estaduais e municipais dessa fonte adicional de recursos serão distribuídas em razão do número de matrícula nas redes públicas da educação básica (Incluído pela Emenda Constitucional nº 53, de 2006).

Desse modo, os recursos que compõem o orçamento da educação são parte do orçamento geral da União, dos Estados e municípios. São originários, predominantemente, dos tributos $^{4}$ que compõem o Tesouro Nacional (Tesouro Estadual e Tesouro Municipal), mas, sobretudo, dos impostos (DAVEIS, 2004; 2008;; OLIVEIRA, 2007; PINTO, 2007; SANTOS; 2012; 2015). É importante ressaltar que os recursos advêm não só dessas instâncias, mas também de contribuições sociais, de recursos de transferências entre entes federados, de ganhos do próprio Fundeb ${ }^{5}$, de recursos da loteria federal e de outras dotações orçamentárias, como verbas do Banco Mundial ou de outro organismo ${ }^{6}$.

A CF/88, dessa forma, ampliou os percentuais de recursos vinculados para educação. De acordo com o art. 211 de CF/88, a União passaria a aplicar na educação pública nunca menos de $18 \%$ e os Estados, Municípios e Distrito Federal nunca menos que 25\%. No referido artigo, está disposto que União, Estados, DF e municípios devem se organizar em regime de colaboração, e que a União deve exercer função supletiva e redistributiva ( $\left.\operatorname{art.} 211, \S 1^{\circ}\right)$ das funções próprias de cada ente federado (BRASIL, 1988. art. $211, \S 1^{\circ}, \S 2^{\circ}, \S 3^{\circ}$; BRASIL, 1996. art. $10 ; 11)$ no sentido de garantir o direito à educação. Esse aspecto é fortalecido pelos arts. 75 e 76 da LDB. O art. 75, especificamente, prevê a ação supletiva da União e dos estados, sem

\footnotetext{
${ }^{4}$ Os Tributos podem ser divididos em impostos, taxas e contribuições. Os recursos da educação são predominantemente originários dos impostos, e a única contribuição social que é utilizada para aplicar em educação é o Salário Educação (SE). Veremos um pouco mais sobre o SE mais adiante.

${ }^{5} \mathrm{E}$ bom dizer que, em alguns casos, há municípios que ganham muito com recursos do Fundeb, contudo ganhar aqui se refere a relação entre o que o município arrecadou e enviou ao Fundo e o que recebeu de acordo com a razão de sua matrícula. Retornaremos isso ao falar do Fundeb.

${ }^{6}$ Além dos arts. 208, 211, 212, 213 e 214, ver também, na Constituição de 1988, os arts. 7, 23, 30, 60 do ADCT, $150,154,155,158,159,160$. Todos eles nos ajudam a discutir o financiamento no contexto da CF/88.
} 
necessariamente distinguir níveis, mas exercida com o objetivo de corrigir as disparidades educacionais e do padrão de qualidade.

A CF/88, além da ampliação dos percentuais de impostos para a Manutenção e Desenvolvimento do Ensino (MDE), promoveu um adicional do Salário Educação (SE) das receitas do Fundo de Participação dos Estados (FPE) e do Fundo de Participação dos Municípios (FPM) e uma maior obrigação e responsabilidade da União com a educação pelas disposições do art. 60 do Ato das Disposições Transitórias (ADCT), sobretudo, ao definir a obrigação de que 50\% dos recursos públicos destinados à educação fossem garantidos para a erradicação do analfabetismo e a universalização do ensino fundamental (Artigos 211, 212, 159, e $60 \mathrm{ADCT}$ da CF/88).

É importante lembrar que a vinculação dos percentuais de que trata o art. 211 não inclui os recursos do Salário Educação (SE), nem os valores de transferências de que se refere o $\$ 1^{\circ}$ do art. 212, nem os recursos recebidos em virtude do programa suplementar ou de outras transações econômicas de que permite a lei. A vinculação de que trata o art. 211 vem somente dos tributos do tipo imposto. O SE é um tributo do tipo contribuição social, já os valores transferidos e recebidos pelos estados e municípios em forma de FPE e FPM não podem ser contabilizados duas vezes, haja vista que se tratam dos valores dos impostos arrecadados e declarados no âmbito da União e dos Estados.

Desse modo, podemos dizer que o tema do Financiamento da Educação assumiu posição importante na agenda das políticas públicas educacionais após a Constituinte. Para se ter uma ideia, até o ano de 2013, a CF/ 88 recebeu 79 Emendas Constitucionais e 4 delas foram mais específicas em relação à educação e a seu financiamento, são elas: a EC n 11/1995, a EC $n^{\circ}$ 14/1996, a $\mathrm{EC} \mathrm{n}^{\circ}$ 53/2006 e a EC n 59/2009. Dessas, as três últimas têm relação e impacto direito com o tema do financiamento da educação e expressam, de algum modo, tentativas de operacionalização do Pacto Federativo em relação à garantia do direito à educação (FARAREZENA, 2013; SAVIANI; 2013).

O debate, os estudos e as pesquisas sobre financiamento da educação no Brasil tomaram corpo a partir dos anos de 1990, motivados por vários aspectos: a necessidade de universalizar o ensino fundamental, de erradicação do analfabetismo, de valorizar os profissionais do magistério e de garantir mais qualidade na educação básica. Assim como surgiu a necessidade de definir um valor por aluno por ano, de aumentar recursos da união para a educação, de assegurar a municipalização. Além disso, havia a intenção de aperfeiçoamento técnico que promovesse transparência e eficácia nos mecanismos de distribuição e gestão dos recursos, 
como também de reduzir as desigualdades educacionais, sociais e econômica. Haja vista, mesmo com as disposições posta na $\mathrm{CF} / 88$, o financiamento da educação enfrentava sérios problemas, como o mau uso dos recursos públicos, a baixa capacidade de planejamento e de gestão, ausência de eficiência, eficácia e equidade na aplicação dos investimentos, falta de transparência e de critérios técnicos científicos na (re) distribuição e na prestação de contas.

A LDB e o Fundef aprovados em dezembro de 1996, cumprir também um papel de melhor sistematizar e operacionalizar o financiamento da educação básica no Brasil. Na LDB/1996, foi definido, detalhado e delimitado sobre o financiamento da educação. A LDB dedicou um Título ao financiamento educacional, "Dos Recursos Financeiros", que compreendem os arts. 68 a 77. Dispondo, por exemplo, sobre as origens e as fontes de recursos (art.68); sobre a distribuição dos recursos e sanções (art.69); sobre o que seriam gastos ou não com a MDE (arts. 70 a 72); sobre a responsabilidade dos órgãos fiscalizadores (art. 73); sobre os padrões mínimos de oportunidades educacionais para o ensino fundamental que deve ser definido em regime de colaboração (art. 74), sobre a ação supletiva da União e dos Estados, com o objetivo de corrigir as disparidades de acesso, como, também, de garantir o padrão mínimo de qualidade (arts. 75 e 76) e sobre as transferências de recursos públicos para escolas privadas - comunitárias, confessionais ou filantrópicas (art. 77).

No intuito de resolver alguns problemas da educação e de seu financiamento e avançar nas condições dispostas nos arts. 205 a 214 e no art. 60 do ADCT da CF/88, foi criado o Fundo de Manutenção de Desenvolvimento do Ensino Fundamental e de Valorização do Magistério (Fundef). Instituído pela Emenda Constitucional $\mathrm{n}^{\circ}$ 14, de 12 de setembro de 1996, e implantado em 1998, o Fundef subvinculava 15\% dos 25\% dos recursos constitucionalmente vinculados para o Ensino Fundamental, 15\% dos 25\% dos recursos de estados e municípios já vinculados à Manutenção e Desenvolvimento do Ensino, nos termos dispostos no art. 212 da $\mathrm{CF} / 88$. Desses $15 \%$, no mínimo 60\% deveriam ser aplicados na valorização dos profissionais do magistério em exercício.

O Fundef foi uma política pública de financiamento educacional que objetivou promover uma mudança na estrutura de financiamento do ensino fundamental público por apresentar mais transparência e critérios técnicos para a distribuição dos recursos públicos vinculados constitucionalmente para o setor e introduzir a metodologia do valor mínimo nacional de custo anual por aluno para distribuição dos recursos. Assim, definiram-se percentuais mínimos (60\% do Fundo) para aplicação na valorização do magistério, bem como instituíram-se mecanismos de controle e de fiscalização. Dessa forma, o financiamento 
educacional via Fundef contribuiu em parte para a operacionalização da divisão das responsabilidades com a universalização do ensino fundamental uma vez que envolveu União, Estados, Distrito Federal e municípios nesse intuito (OLIVEIRA, 2007; SANTOS, 2012; SOUSA Jr, 2006).

Contudo, é importante observar que os Artigos 3 e 4, em conformidade com os 206, 211, 2012 e 214 da CF/88, tratam sobre a obrigação e a necessidade de estabelecer um padrão mínimo de qualidade com a finalidade de assegurar equidade e reduzir desigualdades educacionais. Processo que deveria ter sido feito mediante a definição do custo mínimo por aluno e assegurado em regime de colaboração, nos termos definidos nos arts. 16, 17 e 18 da LDB e no 211 da CF/88. Apesar dessas disposições, até o momento, não foi definido pelos entes da federação o que seria o padrão mínimo de qualidade, nem necessariamente o custo mínimo, como também não houve sanções pelo não estabelecimento, nem cumprimento dessa determinação legal. Além disso, por regime de colaboração a União, os Estados e os municípios deveriam estar trabalhando no sentido de garantir o direto à educação infantil.

Assim, podemos observar também que, no art. 74 da LDB, esse padrão mínimo de oportunidades educacionais, baseado no cálculo do custo mínimo por aluno e que seria capaz de assegurar o ensino de qualidade, é endereçado apenas ao ensino fundamental. O que evidência, mais uma vez uma contradição na defesa da educação infantil como direito, como também na própria natureza desse atendimento. Tal aspecto, a princípio, indica prioridade e focalização em um segmento da educação básica em detrimento dos demais, bem como desconsideração com as especificidades de cada segmento. Todavia, ainda que com tais indicativos e limitações, o padrão mínimo ainda não foi definido.

Da mesma forma, O Fundef também apresentou várias limitações e contradições. Um componente que evidenciou um dos grandes limites do Fundef foi a definição do valor do aluno/ano que se apresentou muito mais baixo do que estava previsto na Lei $n^{\circ}$ 9.424/96. Além disso, não foram utilizados, pelo menos até o ano de 2000, os fatores de diferenciação previstos no Fundef para os segmentos de $1^{\mathrm{a}}$ a $4^{\mathrm{a}}$, de $5^{\mathrm{a}}$ ao $8^{\mathrm{a}}$, de educação especial, dentre outros, definidos na Lei que regulamenta o Fundo. Também não foram cumpridos a definição do valor mínimo bem como o padrão mínimo de qualidade e a complementação da União ficou como uma prerrogativa do Governo Federal que definiria segundo seus critérios não presentes de imediato na política (DAVIES, 2004; 2008; 2011; MONLEVADE, 2007; PINTO, 2006;2007). 
O Fundef também limitou o conceito de educação básica, focalizando recursos no ensino fundamental e não considerando a educação infantil e a educação de jovens e adultos (EJA), no investimento em educação municipal. Tal fato, além de fortalecer uma separação entre o que era considerado ensino obrigatório e o que não era, reforçou a centralidade ou prioridade desse nível de ensino nas políticas e nos investimentos educacionais. Uma decisão equivocada, pois “a qualidade no ensino fundamental depende da qualidade na educação infantil” (MARTINS, 2010, p. 508). Para alguns estudiosos, a educação infantil foi o segmento mais afetado no Fundef, pois o Fundef causou diminuição de oferta de vagas e de investimento na educação infantil e na educação de jovens e adultos (DIDONET, 2006; PINTO, 2006; 2007; SOUZA Jr, 2006).

O Fundef concentrou recursos para o ensino fundamental e não direcionou recursos específicos para a educação infantil. Mesmo sendo criado no mesmo período da promulgação da LDB, que elevou a educação infantil como a Primeira Etapa da Educação Básica, não direcionou recursos de forma específica para a mesma. A educação para infância continuou sem uma política de financiamento (SANTOS, 2012). O reconhecimento do direito à educação das crianças pequenas não alterou o quadro no que se refere ao papel do Estado brasileiro com as políticas para a educação infantil, haja vista que a política pública social requer necessariamente a aplicação de recursos adequados.

No bojo desses cenários, o financiamento da educação infantil passa a receber forte atenção, impulsionado, sobretudo, pela ausência de prioridade nos recursos para a educação, e por sua exclusão no Fundef. Foi intensificado o debate, elaboradas algumas PECs e realizados alguns eventos e discussões sobre o tema (ABREU, 2004b; LIMA, 2006; SANTOS, 2012). Municípios e entidades, como Undime, Confederação Nacional dos Trabalhadores em Educação (CNTE) e Campanha Nacional Pelo Direito à Educação, além de criticarem os resultados e os efeitos do Fundef reivindicavam mais recursos para a educação básica, melhorias salariais, dentre outras questões correlatas.

\section{O financiamento da educação infantil 30 anos depois da Constituição Federal}

1988: avanços, contradições e desafios visto a partir do Fundeb

Desde a iminência da criação da Proposta de Emenda Constitucional (PEC) nº 233/95, que originou o Fundef, surgiram inúmeras PECs com foco no financiamento educacional, muitas delas relativas ao financiamento da educação infantil, seja propondo a criação de um 
fundo específico para a educação infantil, seja recomendando a inclusão desse segmento no Fundef, ou ainda sugerindo o financiamento de toda educação básica, o que incluiria a educação em creche e pré-escola ${ }^{7}$. Exemplo disso é a PEC nº 570, ainda em 1998, e a PEC nº 112, apresentada ao Congresso no ano de 1999, pela bancada do Partido dos Trabalhadores, que propuseram a criação de um Fundo para toda a educação básica. A PEC no 112/1999 sofreu

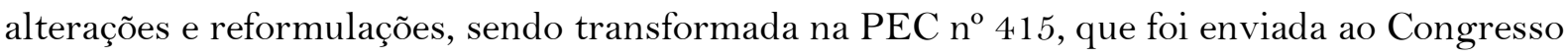
Nacional, pelo Executivo, no ano de 2005, propondo a criação de um Fundo de Manutenção e Desenvolvimento da Educação Básica (Fundeb).

A PEC 415/2005 apresentou muitas limitações no sentido de garantir o direito à educação básica nos termos postos nos artigos 205 a 214 da CF/88, o que fez com que vários atores sociais - movimentos da sociedade, estudiosos em educação, gestores da educação e das finanças de todos entes federados, bem como parlamentares de várias bancadas e diversas instituições da sociedade civil organizadas da área de educação e áreas afins - se envolvessem num intenso debate em torno da reformulação e aprovação do Fundeb.

Entre as diversas limitações presentes na proposta do Fundeb que entraram na pauta dos debates, podemos citar: "a inclusão das creches", "inclusão das instituições conveniadas", "destinação para a educação básica pública”, “complementação da União correspondente a 10\% do total do fundo" (MARTINS, 2011, p.198), "vinculação de 20\% em lugar de 25\%", "retirada do IRRF", a "não utilização do SE como fonte da complementação", "complementação para todos os estados”, "permanência da vinculação do salário educação apenas para o ensino fundamental” (MARTINS, 2011, p. 199), “fixação das ponderações pela junta/comissão e não por lei”, "repasse direto dos recursos do Fundeb aos municípios que transportassem alunos da rede estadual” (MARTINS, 2011, p. 200) e muitos outros.

Algumas dessas proposições tiveram maior relação com o tema da educação infantil no Fundeb, como a inclusão das creches sem envolvimento dos impostos municipais, que teve como proponente e apoiador: Undime, CNM, Campanha Nacional pelo Direito à Educação, Movimento Interfóruns de Educação Infantil do Brasil (Mieib), Fundeb pra Valer, União Nacional dos Conselhos Municipais de Educação (Uncme) e, como opositor, o Conselho Nacional de Secretários de Educação (Consed). A inclusão das instituições conveniadas foi indicada e apoiada pela Undime e pela Frente Nacional de Prefeitos (FNP). A defesa e a

\footnotetext{
7 Ver Abreu, (2004a, p. 136-137; 2004b), Lima (2006) e Santos (2012; 2015).
} 
proposição para a destinação do fundo, apenas para a educação básica pública, foi proposta pela Campanha Nacional pelo Direito à Educação e o CNTE (MARTINS, 2011).

Contudo quatro pontos ganharam notoriedade nacional e fizeram com que a sociedade civil se mobilizasse em um intenso debate em prol da reformulação e da aprovação do Fundeb, foram eles: i) a exclusão das creches para o recebimento dos recursos; ii) a necessidade da instituição do Piso Salarial Nacional para os Profissionais da Educação; iii) a não definição do padrão mínimo de qualidade; e iv) a necessidade de elevar a participação da União na Educação Básica.

Nesse contexto, foi criado o "Movimento Fundeb Pra Valer8", coordenado pela Campanha Nacional pelo Direito à Educação. O Movimento reuniu mais de 200 entidades e organizações em torno da referida pauta. Organizados em fóruns e redes, o movimento participou ativamente de todo processo, de debates e de audiências públicas, inclusive no Parlamento. Emitiram notas técnicas, pareces e emendas ao tex to da PEC 415, e influenciaram, marcadamente, a aprovação do texto final da Fundeb. O Movimento elaborou 9 emendas e apresentou como propostas ao tex to da PEC 415/2005. Três (3) delas foram particularmente mais fortes: a inclusão das creches, a instituição do Piso Salarial Nacional e o aumento da Complementação da União, a partir de fixação de percentual de $10 \%$ sobre o valor da arrecadação do Fundo ${ }^{9}$.

$\mathrm{Na}$ luta pela inclusão desses pontos no Fundeb, a sociedade civil precisou se articular em torno de um ponto agregador. Para isso, elegeram a inclusão das creches como ponto comum (NASCIMENTO, 2009; SANTOS, 2012; 2015). Assim, promoveu-se um intenso debate com a participação da sociedade civil, de entidades sindicais e empresariais, de diversos movimentos sociais, de ONGs, de partidos políticos, dentre outras instâncias, na defesa da inclusão das crianças de o a 3 anos de idade no Fundeb. Vale ressaltar que, antes da criação do "Movimento Fundeb pra valer", várias organizações e parlamentares vinham se manifestando contra a não inclusão das creches no $\mathrm{Fundeb}^{10}$. Após muita discussão, debate, alterações e tramitação na Câmara dos Deputados, a PEC/415/2005 foi aprovada e transformada pela

\footnotetext{
8 Foi lançado em ato Público conhecido como "ao Fraldas Pintadas" em 31 de agosto de 2005.

${ }^{9} \mathrm{~A}$ CNTE também propôs emendas ao texto, dentre as quais, o aumento do percentual do Fundo para $25 \%$ e do mínimo de $80 \%$ dos percentuais do Fundeb para a valorização de todos os profissionais da educação e não só dos professores.

${ }^{10} \mathrm{~A}$ Campanha Nacional Pelo Direito à Educação, o Conselho Nacional do Direito da Criança (Conanda), a Organização Mundial pela Educação Pré-escola (Omep), o Movimento Inter Fóruns de Educação Infantil (Mieib), a Undime, dentre outros.
} 
Medida Provisória nº 339/2006. Ela sofreu novas alterações e acréscimos no Senado e foi convertida na Lei ${ }^{\circ} 11.494$, de junho de 2007.

\section{A Emenda Constitucional 53/2006}

Criado pela Emenda Constitucional 53/2006, o Fundeb altera a redação do art. 60 do ADCT da Constituição Federal de 1988, e da nova redação aos arts. 7, 23, 30, 206, 208, 211 , 212, e o art. 7, no inciso XXV, passou a vigorar com a seguinte redação: “assistência gratuita aos filhos e dependentes desde o nascimento até 5 (cinco) anos de idade em creches e préescolas”. O art. 23, no parágrafo único, passou a ter a seguinte redação: “Leis complementares fixarão normas para a cooperação entre a União e os Estados, o Distrito Federal e os Municípios, tendo em vista o equilíbrio do desenvolvimento e do bem-estar em âmbito nacional.”. O art. 30, inciso VI, passou a conter o seguinte texto: "manter, com a cooperação técnica e financeira da União e do Estado, programas de educação infantil e de ensino fundamental".

Podemos observar que os arts. 7, 23, 30, inciso VI; o art. 208, $\$ 4^{\circ}$; o art. $211, \S 2^{\circ}$; os arts. 212, 214 e no art. 60 das ADCT da $\mathrm{CF} / 88$, ao tratarem em seu conjunto da responsabilidade dos entes federados com a educação e, especificamente, sobre a competência dos municípios, não instituem uma hierarquização entre o ensino fundamental e a educação infantil. Constatamos que é de responsabilidade prioritária dos municípios a educação infantil e o ensino fundamental. Não existe, a princípio, a ideia de hierarquização, pois o município deve ocupar-se de ambas as etapas.

Contudo, foi na $\mathrm{EC}^{\circ}$ 14/96 e na Lei $\mathrm{n}^{\circ}$ 9.394/1996 que apareceu a afirmação da prioridade do ensino fundamental em detrimento da educação infantil. A EC nº 14/96 chega a dispor, no art. 3, que os municípios deverão atuar, prioritariamente, no ensino fundamental e na educação infantil, mas trata-se de uma disposição deslocada ou apenas contraditória, uma vez que o texto da EC 14/96 e da Lei que a regulamenta direciona toda atenção e os recursos para o ensino fundamental, sejam os da MDE, sejam os do SE e mesmo os 60\% do Fundef deveriam ser aplicados, especificamente, na valorização dos profissionais do magistério do ensino fundamental.

A LDB (Lei $n^{\circ}$ 9.394/96) foi mais determinante nessa fragmentação visto que amarrou essa orientação em seu art. 11 ao dispor que os municípios deverão se incumbir de:

V - Oferecer a educação infantil em creches e pré-escolas, e, com prioridade, o ensino fundamental, permitida a atuação em outros níveis de ensino somente 
quando estiverem atendidas plenamente as necessidades de sua área de competência e com recursos acima dos percentuais mínimos vinculados pela Constituição Federal à manutenção e desenvolvimento do ensino. (Grifos nosso).

É contraditório que a LDB de 1996, documento legal que dá o atual direcionamento e ordenamento da educação brasileira, ao mesmo passo em que eleva a educação infantil à condição de primeira etapa e dispõe que os municípios deveriam integrá-la aos sistemas municipais de ensino, determina que os municípios deveriam atender prioritariamente ao ensino fundamental. Na verdade, o destaque de prioridade é desnecessário, haja vista a $\mathrm{CF} / 88$ não dá ênfase à prioridade de cada unidade da federação, com as etapas e as modalidades da educação que assumiram especificamente. Todavia, dá ênfase que União, Estados, Distrito Federal e Municípios devem, em regime de colaboração, procurar assegurar o direito à educação, como também a União exercerá função supletiva mediante assistência técnica e financeira aos Estados, Distrito Federal e Municípios de forma a garantir equalização de oportunidades educacionais e padrão mínimo de qualidade do ensino (Art. 21 1, $1^{\circ} \mathrm{CF} / 1988$ ) (Redação dada pela Emenda Constitucional n ${ }^{\circ}$ 14, de 1996). Esses aspectos evidenciam que a educação infantil, enquanto direito, não deve ser de responsabilidade somente dos municípios, mas de todos os entes federados.

Outro aspecto importante está na alteração do art. 208, inciso IV, sobre: "educação infantil, em creche e pré-escola, às crianças de até 5 (cinco) anos de idade”, alterando, no texto legal, a faixa etária da educação infantil de o a 6 anos para 0 a 5 anos de idade. Essa alteração, presente também no art. 7, citado anteriormente, já havia sido preconizada na Lei $\mathrm{n}^{\circ}$ 10.172/2001, que criou o PNE/2001, e nas leis $n^{\circ} 11.114$ e 11.274, respectivamente nos anos de 2005 e 2006, que instituíram e criaram o ensino fundamental de 9 anos. Porém, até 2007, não havia sido alterado o texto Constitucional, permanecendo de 0 a 6 anos de idade como faixa etária constitucional da educação infantil.

No tex to do art. 211 , no $\S 5^{\circ}$, passa-se a afirmar que a educação básica pública atenderá prioritariamente ao ensino regular. Essa escrita é aperfeiçoada na redação dada pela EC 59/2009, que amplia a obrigatoriedade da educação básica dos 4 aos 17 anos de idade e a responsabilidade da União, Estados e Municípios com a cobertura dessa faixa etária. Já o art. 212, $\$ 5^{\circ}$, dispõe que a educação básica pública terá como fonte adicional de financiamento a contribuição social do salário-educação, recolhido pelas empresas na forma da lei. Até 2006, parte dos recursos do Salário Educação (SE) era direcionado apenas para o ensino fundamental, como, também, podia ser usado como complementação da União ao Fundef. Tal aspecto, 
mesmo que de forma limitada, revela como o ensino e a garantia da educação estão associados à ampliação dos recursos públicos para a educação, assim como a elevação do comprometimento do Estado e da União com a MDE e a regulamentação do regime de colaboração entre os entes federados.

É importante destacar, nesse processo, que a EC 59/2009, seguindo a mesma tendência, altera o tex to constitucional, ampliando a faixa etária da educação obrigatória de 4 a 17 anos de idade. Dispõe, ainda, que os recursos vinculados para a MDE devem ser aplicados, prioritariamente, no ensino obrigatório e que esses recursos devem ser definidos levando-se em consideração uma proporção em relação ao PIB.

A referida Emenda tem impacto direto na educação infantil. Por um lado, ao não incluir as creches na faixa etária de obrigatoriedade, fica excluída da prioridade no recebimento dos recursos da MDE. Por outro lado, ao incluir o segmento de 4 e 5 anos, introduz na educação infantil a ideia de obrigatoriedade sobreposta à ideia do direito, haja vista que todas as crianças nessa faixa etária deverão ser, obrigatoriamente, matriculadas na pré-escola. Além disso, a EC/59 promove tanto uma fragmentação da educação infantil quanto uma desigualdade no tratamento, por parte do recebimento dos recursos, do direcionamento de políticas e da prioridade na atuação municipal. Esse processo vai de encontro ao mecanismo do Fundeb que vincula os recursos da MDE para toda a educação básica. E ainda: a EC59/2009 poderá justificar a manutenção dos baixos investimentos e fatores de ponderação para o segmento de o a 3 anos de idade.

De forma semelhante ao contexto da EC/59/2009, o Novo Plano Nacional da Educação (2014-2024) ao dispor em sua meta 01 a universalização da pré-escola até 2016, ou seja, colocar todas as crianças do país de 4 e 5 anos de idade na educação infantil, bem como matricular 50\% das crianças de 0 a 3 anos de idade na creche, coloca em pauta os limites e possiblidades orçamentárias do Fundeb para o alcance das referidas metas. Isso porque, para além de um bom planejamento, esse processo sugere uma elevação significativa dos aportes financeiros para a educação das crianças de 0 a 6 anos.

A questão não está no fato de o direito estar inscrito em lei, mas nos mecanismos de proteção e de financiamento para que o direito seja assegurado. A garantia do direito à educação infantil não se faz apenas mediante ao reconhecimento e criação de dispositivos legais e jurídicos (BOBBIO, 1992), mas diante da criação de política pública social, que assegure recursos financeiros para sua operacionalização (CURY, 2007). Assim, para assegurar o direito 
à educação das crianças de 0 a 6 anos de idade, é imprescindível uma ampliação que a considere. Poderá o Fundeb representar um avanço nessa direção?

Fundeb Avanços e desafios.

A educação infantil entrou, de forma mais clara, na pauta política a partir das tensões e conflitos gerados durante a aprovação do Fundeb, no Congresso Nacional, sobretudo, fruto da mobilização da sociedade civil organizada nos seus mais variados segmentos e instâncias. Esse processo assegurou uma maior institucionalização e financiamento para a educação infantil, como também mobilizou a União no sentido de ampliar o investimento federal em educação.

De acordo com pesquisa recente sobre a relação Fundeb e a educação infantil, o Fundeb tem contribuições para a elevação das matrículas desse segmento da educação e para a municipalização do segmento de o a 3 anos de idade, uma vez que havia ainda muitos municípios em que o atendimento das creches ainda estava sob a responsabilidade da Secretaria de Assistência ou da Secretaria de Desenvolvimento Social (cf. BASSI, 2011 ; SANTOS, 2012).

Para Santos (2012; 2015) a criação do Fundeb representou um passo significativo da educação brasileira, em relação ao atendimento educacional à infância, por diversos motivos, a saber: deu à educação infantil, no Brasil, a importância e a atenção que lhe são inerentes; vinculou recursos para assegurar o direito à educação a todos os brasileiros desde o seu nascimento; significou o início da consolidação de um conceito de educação básica amplo, sistêmico e dinâmico; mostrou uma possibilidade de universalização da educação básica, de fortalecimento e valorização dos profissionais da educação; e permitiu um aumento de recursos da União para a educação. Porém, deve-se levar em consideração que, apesar dos benefícios que o Fundeb trouxe para esse segmento, ainda há muito que avançar.

De acordo com Monlevade (2007, p. 119), o Censo Escolar de 2005 registrou um atendimento na pré-escola de mais de $51 \%$, ao passo que, ao analisarmos a taxa da matrícula da creche entre 1997 e 2009, verificamos um crescimento expressivo de 348.012 matrículas para um total de 1.896.363. Isso significa que, apesar da EI não ter recebido recursos do Fundef, ainda sim, apresentou uma evolução no atendimento (MONLEVADE, 2007). Segundo Macêdo e Dias (2011), nos anos de 2007 a 2009, houve um crescimento médio da matrícula em creche em torno de $10 \%$. Essas autoras atribuem ao Fundeb esse avanço. Essa evolução se confirma ao observarmos o relatório do Censo Escolar referente ao ano de 2010, no qual 
apresenta a creche como segmento da educação que mais cresceu entre 2009 e 2010, o que correspondeu à ordem de $9.0 \%$.

$\mathrm{O}$ crescimento da EI tem tido maior destaque no que tange à faix a etária de 0 a 3 anos. Estudos recentes do IBGE constataram que, em 2007, o país contava com aproximadamente 11,2 milhões de crianças de 0 a 3 anos de idade e somente $17,1 \%$ destas frequentavam creche. Em relação aos 4 a 5 anos, 70,1\% estão matriculadas. A implantação do Fundeb representou, sem dúvida, um avanço para o segmento da educação infantil, o que pode ser confirmado com a constatação da significativa ampliação da cobertura refletida em um crescimento de $10 \%$ entre 2007 e 2009 e de 9,0\% entre 2009 e 2010 (MACÊDO; DIAS 2011).

Contudo os recursos do Fundeb são insuficientes para favorecer grandes mudanças nos rumos da educação, apesar de necessários. Entre os grandes problemas presentes no Fundeb estão: a existência de poucos recursos novos e os baixos fatores de diferenciação ${ }^{11}$, sobretudo, os estabelecidos para a educação infantil, pois não representam as despesas reais com essa etapa educativa. Por exemplo, os fatores de ponderação para a educação infantil para o ano de 2007 foram de 0,80 para a creche e de 0,90 para a pré-escola. Os baixos fatores de ponderação inviabilizam a ampliação do atendimento das redes municipais de educação infantil, bem como a garantia de qualidade. Além de não ter relação com o custo real de cada segmento, proporciona a permanência do baixo custo na educação infantil e a focalização dos recursos no ensino fundamental (DAVIES, 2008; ARAÚJO, 2006; PINTO, 2006; 2007).

Outra limitação está no fato de o Fundeb admitir que recursos públicos possam ser direcionados a instituições de natureza privada, o que diminui a aplicação do fundo público para a educação pública, particularmente, também para a educação infantil. A esse respeito, Pinto (2007, p. 889) ressaltou que se corria o risco de uma expansão da educação infantil pela via dos convênios com instituições privadas sem fins lucrativos.

[...] O grande risco, em especial no que se refere às creches, onde a demanda
reprimida é gigantesca em virtude do baixo atendimento, é que o crescimento
das matrículas se dê pela via das instituições conveniadas, já que o repasse
que o poder público faz a essas instituições é muito inferior aos custos do
atendimento direto. Cabe ressaltar que essas diferenças não se referem a
níveis distintos de eficiência do setor público versus privado, mas
simplesmente porque o padrão de qualidade de oferta das instituições
públicas é muito superior e, logo, os custos também o são [...].

${ }^{11}$ Fator de diferenciação ou de ponderação refere-se a um mecanismo utilizado pelo Fundeb para distribuir os recursos do fundo de forma diferente para cada segmento, etapa, modalidade e estabelecimento considerando a natureza de cada um. Os fatores variam de 0,70 centésimo a 1,3 centésimo. 
Outro aspecto importante para se considerar é sobre a implantação do Fundeb que ocorreu de forma gradual entre os anos de 2007 a 2010 . A partir de 2007, a cada ano, parte das matrículas da educação infantil passava a receber recursos dessa política. O processo foi concluído em 2010, quando a União passou a complementar o Fundo com 10\% sobre seu valor total da arrecadação. Esse fato reforça a preocupação de natureza econômica dessa política e a ausência de uma estratégia social.

Além disso, é importante considerar que, historicamente, a educação infantil não teve a devida atenção por parte do poder público brasileiro e que o nosso modelo de federalismo, bem como as disparidades regionais e estaduais, tem relação direta com o financiamento educativo. Nossos estados são distintos e desiguais, seja no processo de arrecadação dos impostos, seja na distribuição das riquezas. Essas características, dentre outras, revelam limitações na vinculação de recursos públicos para assegurar o direito à educação ao segmento de 0 a 6 anos de idade.

Houve pouco aumento de recursos, haja vista tratar de recursos já vinculados constitucionalmente para a educação. Assim, é importante destacar os problemas relativos com o baixo poder de fiscalização dos conselhos e comunidade escolar, como também, de problemas relativos à gestão dos recursos. Tais fatores se constituem obstáculos para o atendimento das diversas demandas da educação brasileira, principalmente da Educação Infantil, segmento que tem o maior custo dentro da educação básica.

Podemos observar, por exemplo, nos arts. 7, 23, 30, inciso VI; o art. 208, $\$ 4^{\circ}$; o art. $211, \S 2^{\circ}$; os arts. 212, 214 e no art. 60 das ADCT da CF/88, ao tratarem sobre a responsabilidade dos entes federados com a educação e, especificamente, sobre a competência dos municípios, não instituem uma hierarquização entre o ensino fundamental e a educação infantil. O que consta é que é de responsabilidade prioritária dos municípios a educação infantil e o ensino fundamental, pois o município deve ocupar-se de ambas as etapas. Contudo, a EC $n^{\circ} 14 / 96$ e a Lei. $n^{\circ}$ 9.394/1996 apresentam um retrocesso ao afirmaram prioridade ao ensino fundamental em detrimento da educação infantil.

A verdade é que União, Estados, Distrito Federal e Municípios, em regime de colaboração, devem assegurar o direito à educação. Nesse âmbito, a União exerce função supletiva mediante assistência técnica e financeira aos Estados, Distrito Federal e Municípios no sentido de equalização das oportunidades educacionais e da garantia de padrão mínimo de qualidade do ensino (Art. 211, §1 ${ }^{\circ} \mathrm{CF} / 1988$ ) (Redação dada pela Emenda Constitucional n ${ }^{\circ}$ 14, de 1996). Nesse sentido, é importante destacar que, apesar da Constituição Federal de 1988, 
do Estatuto da Criança e do Adolescente Lei nº 8.069 de 1990, na Lei de Diretrizes e Bases da Educação Brasileira 9.394 de 1996, e tantos outros dispositivos legais disporem sobre a educação como direito humano fundamental, na prática, o direito à educação para primeira infância ainda não está assegurado. Uma das principais razões é a insuficiência de recursos públicos.

Apesar dos limites dessa política, o Fundeb constitui-se um avanço para o financiamento da educação e para a própria educação básica no Brasil, seja pelo aperfeiçoamento no mecanismo de distribuição dos recursos, seja na ampliação do comprometimento da União com a educação básica. Além do mais, é possível constatar, a partir do período de implementação do Fundeb, uma ampliação dos recursos direcionados para toda educação básica, bem como, na maioria dos estados e municípios, a duplicação ou quase triplicação dos valores recebidos do Fundeb nos últimos anos. O mesmo ocorreu com o orçamento do MEC e do FNDE (BRASIL, 2010; SANTOS, 2012; 2015).

De forma correlata, também a Educação Infantil tem elevado seu quantitativo de matrículas. De acordo com os dados do Censo Escolar, desde 2007, essa etapa da educação, e particularmente, o segmento creche, é o que mais tem ampliado o número de matrículas, mesmo que abaixo do esperado. O Censo Escolar de 2013 confirma essa tendência, principalmente para o atendimento das crianças de 0 a 3 anos de idade, quando comparado ao número de matrícula entre os anos de 2007 a 2013. O número de matrículas apresentou elevação na ordem de 72,8\%, passando de 1.579.581, em 2007, para 2.730.119, em 2013 (BRASIL, 2013).

Nesse contexto, nos é oportuno e importante analisar se o Fundeb, como a principal política de vinculação de recursos públicos para esse segmento, terá capacidade de assegurar a expansão do atendimento educacional para às crianças de 0 a 5 anos de idade. Além de oportuno, nos parece atual e urgente voltar-se para o financiamento da educação infantil na eminência da implementação da Emenda Constitucional 59/2009 e da aprovação da Lei $n^{\circ}$ 13.005/14, que instituiu o Novo Plano Nacional da Educação (PNE).

A EC/59 de novembro de 2009 altera a obrigatoriedade e gratuidade da educação básica, em que passa a ser dos 4 (quatro) aos 17 (dezessete) anos de idade, ampliando a responsabilidade do Estado quanto à garantia do direito à educação básica. Nesse caso, altera também a estrutura da educação infantil e torna obrigatória a matrícula das crianças com 4 (quatro) e 5 (cinco) anos na pré-escola. Nesse sentido, é fundamental pensar se os recursos vinculados para o financiamento da educação infantil no Fundeb serão suficientes e adequados 
para o provimento da universalização da pré-escola e ampliação em $50 \%$ do atendimento em creches, tanto no que dispõe a EC/59 de 2009, quanto nos termos do Novo Plano Nacional da Educação (2014-2024).

Assim, para assegurar o direito à educação das crianças de 0 a 6 anos de idade, é imprescindível uma ampliação que considere, sobretudo, os indicadores de qualidade, as Diretrizes Curriculares Nacionais para a Educação Infantil (DCNEI), as Referências Curriculares Nacionais para a Educação Infantil (RCNEI) e todos os critérios para a garantia do atendimento das crianças de $\mathrm{O}$ a 6 anos de idade como um direito. Ou teremos um processo de expansão apenas via matrícula e o fornecimento de uma assistência social. É imprescindível também a construção de espaços adequados para o atendimento, quantidade de profissionais com formação adequada, recursos didáticos pedagógicos, ou teremos um expansionismo como ocorreu com o atendimento pré-escolar durante o regime militar (ROSEMBERG,1992; CAMPOS, 1992).

Tais indagações devem-se ampliar no contexto atual em que tramita a PEC $\mathrm{n}^{\mathrm{o}} 15$, de 2015, que tem por escopo principal transformar o Fundeb em um instrumento permanente de financiamento da educação básica pública. O Fundeb tem seu fim previsto para 2020, no entanto, tal fato levaria ao caos a educação brasileira e colocaria em xeque as políticas, planos e programas educacionais. Nesse contexto, o que está em pauta é tornar o Fundeb um mecanismo contínuo e estável, trazendo-o para o corpo permanente da Constituição.

Com isso, o Novo Fundeb pretende trazer elementos que aperfeiçoe o atual Fundo como planejamento e participação da sociedade na formulação, acompanhamento contínuo, monitoramento e avaliação periódica das políticas sociais (SENA, 2015). Contudo, uma das propostas de mudança está no inciso III do art. 212-A da PEC que substitui a expressão do inciso III do art 60 do ADCT - "educação básica”, por "educação básica obrigatória e gratuita dos quatro aos dezessete anos e ampliação da oferta para as crianças de até quatro anos de idade" adequando ao tex to da EC/59, este aspecto, desobriga o Estado do financiamento para o segmento de 0 a 3 anos de idade. Nos parece que, passados 30 anos da CF de 1988 e o direito à educação infantil, sobretudo, no que se refere ao segmento creche, essa etapa educacional está longe de ser assegurada no contexto de uma política de financiamento.

\section{Considerações finais}


Apesar dos avanços nesses 30 anos da Constituição Federal de 1988 e, por conseguinte, nas EC que tratam do financiamento da educação, seguem como desafios para o financiamento da educação infantil: a necessidade de superação da focalização e da aplicação dos recursos educacionais no ensino fundamental; a necessidade de ampliação dos descritores que vinculam recursos para a educação infantil; a necessidade de que se considerem as lutas, os estudos e pesquisa que vêm sendo desenvolvidas sobre a área na definição da política de recursos para a educação infantil; a necessidade de esclarecimento e operacionalização do regime de colaboração entre os entes da federação; o aumento da participação da União no financiamento da educação; e a efetiva valorização dos trabalhadores em educação.

Assim, apesar dos avanços da educação para a infância, no conjunto das políticas sociais, a ausência ou a pouca presença de recursos para assegurá-la configura-se num elemento limitador e dificultoso na expansão do atendimento e garantia à infância nesse âmbito. Tal fato nos leva a afirmar que, não basta um direito estar inscrito em Lei, é imprescindível a presença de recursos públicos para garanti-lo. É necessário, além disso, pensar o financiamento da educação infantil não só como uma política de setor, ou de governo e sim, como política de Estado para assegurar a educação da criança pequena como um direito. O financiamento adequado da Educação Infantil pode representar melhor operacionalização das políticas educacionais para a infância, bem como contribuir para a realização das propostas, metas e determinações para esse nível de ensino, além de poder garantir a efetivação da educação como direto social fundamental preconizado na Constituição Federal de 1988.

\section{Referências}

ABREU, Mariza. Educação Infantil no Brasil: legislação, matrículas, financiamento e desafios. Brasília. DF: Câmara dos Deputados, 2004.

Estudo sobre as possibilidades de continuidade do Fundef e o financiamento a educação básica no país. In: COELHO, Rita de Cássia e BARRETO, Ângela Rabelo (Orgs.). Financiamento da Educação Infantil: Perspectivas em Debate. Brasília: UNESCO Brasil, 2004.

ARAÚJO, Luiz. Insuficiente, mas necessário! In: DIDONET, Vidal; LIMA, Maria José Rocha. FUNDEB: Avanços na universalização da Educação Básica. Brasília: Inep, 2006. p. 105-115.

BASSI, Marcos Edgar. Financiamento da Educação Infantil em seis capitais brasileiras. Cadernos de Pesquisa. v. 41. n. 142, jan/abr. 2011.

BOBBIO, Norberto. A era dos Direitos. 8. ed. Rio de Janeiro: Campus, 1992.

BRASIL. Constituição da República Federativa do Brasil. 1988. 
Revista Educação e Políticas em Debate - v. 7, n. 2, p. 263 -288, mai./ago. 2018 - ISSN 2238-8346

Lei de Diretrizes e Bases da Educação Nacional, n.9.394. 1996.

. Ministério da Educação e do Desporto. Secretaria de Educação Fundamental. Referencial Curricular Nacional para a Educação Infantil - Introdução. Brasília: MEC/SEF, 1998.

Secretaria de Educação. Diretrizes Curriculares Nacionais para Educação Infantil. Mec/SEF, Brasília, 1999.

Plano Nacional de Educação. 2001.

Ministério da Educação. Secretaria de Educação Fundamental. Política Nacional de Educação Infantil. Brasília, DF: MEC/SEF/COEDI, 2006.

. Ministério da Educação. Secretaria de Educação Fundamental. Por uma política de formação do profissional de Educação Infantil. Brasília, DF: MEC/SEF/DPE/COEDI, 1994.

Lei 11.494 de 20 de junho de 2007. Regulamenta o Fundo de Manutenção e Desenvolvimento da Educação Básica e de Valorização dos Profissionais da Educação -Diário Oficial da República Federativa do Brasil, Brasília, DF, 2007.

Censo Escolar, Brasília, DF: MEC/INEP. 2007.

Emenda Constitucional n. ${ }^{\circ}$ 59, de 11 de novembro de 2009. Brasília-DF, 11 nov. 2009b.

Censo Escolar, Brasília, DF: MEC/INEP. 2010.

Censo Escolar, Brasília, DF: MEC/INEP. 2013.

Plano Nacional de Educação para o decênio (2014- 2024). Brasília. 2014.

CAMPOS, Maria Malta. Atendimento à infância na década de 80: as políticas federais de financiamento. In: Cadernos de Pesquisas $n^{0}$ 82. São Paulo: Fundação Carlos Chagas, agosto de 1992, p. 5- 20.

CURY, Carlos Jamil. Estado e Políticas de Financiamento em Educação. Educ. Soc. Campinas, v. 28, n. 100 - Especial, p. 831-855, out. 2007.

DAVIES, Nicholas. Financiamento da Educação: novos ou velhos desafios? Xamã, São Paulo 2004, $168 \mathrm{p}$.

FUNDEB - A redenção da Educação Básica. São Paulo, Autores associados, 2008.

DIDONET, Vital. A Educação Infantil na Educação Básica e o FUNDEB. In: FUNDEB: Avanços na universalização da Educação Básica. Brasília: Inep, 2006, p. 21-30.

FARENZENA, Nalú; LUCE, Maria Beatriz. Financiamento da educação e responsabilidades federativas: 25 anos de agenda constituinte. RBPAE, Recife, v. 29, n. 2, p.187-191, $\mathrm{mai} /$ ago.2013.

LIMA, Maria José Rocha. In: FUNDEB: Avanços na universalização da Educação Básica. Brasília: Inep, 2006 
MACÊDO, Lenilda Cordeiro de; DIAS, Adelaide Alves. A política de financiamento da educação no Brasil e a educação infantil. In: Revista brasileira de política a administração da educação 27.v, 2. n, p.153-360 mai/ago.2011.

MARTINS, Paulo de Sena. Fundeb, Federalismo e Regime de Colaboração. Campinas - SP: Autores Associados, 2011.

O financiamento da educação básica como política pública. Revista Brasileira de Política e Administração da Educação, Porto Alegre, v. 26, n. 3, p. 497-514, set/dez. 2010.

MONLEVADE, João Antônio. Para entender o FUNDEB. Ceilândia-DF: Idea, 2007. 144p.

NASCIMENTO, Iracema. "Direito à educação começa do berço e é pra toda a Vida" A atuação da Campanha Nacional pelo Direito à Educação na criação do Fundo da 159 Educação Básica. Brasil, 2009. Disponível em http://www.campanhaeducacao.org.br/?pg=Publicacoes\&id=17).

OLIVEIRA, Romualdo Portela; ADRIÃO, Thereza (Org.). Gestão, financiamento e direito à educação: análise da Constituição Federal e da LDB. 3 ed. Xamã, São Paulo. 2007, 143 p.

PINTO, José Marcelino Rezende; ADRIÃO, Theresa. Noções gerais sobre o financiamento da educação no Brasil. Eccos: Revista Científica, São Paulo, v. 8, n. 1, p. 23-46, jan/jun. 2006.

A política recente de fundos para o financiamento da educação e seus efeitos no pacto federativo. Educação e Sociedade, v.28,n.100, p877-897, out. 2007.

ROSEMBERG, Fúlvia. Educação infantil pós-FUNDEB: avanços e tensões. In: SOUZA, Gizele (Org.). Educar na infância: perspectivas histórico-sociais. São Paulo: Contexto, 2010.

A educação pré-escolar brasileira durante os governos militares. In: Cadernos de Pesquisas n. 82. São Paulo: Fundação Carlos Chagas, agosto de 1992. p. 2130.

SAVIANI, Dermeval. A educação na Constituição Federal de 1988: avanços no texto e sua neutralização no contexto dos 25 anos de vigência. RBPAE, Recife, v. 29, n. 2, p.187-191, mai/ago.2013.

SANTOS, Joedson Brito dos. O Fundeb e a Educação Infantil no município de Itabuna. 2012.171 p. Dissertação (Mestrado) - Faculdade de Educação, Universidade Federal da Bahia, Salvador, 2012.

O Fundeb e a Educação Infantil. Curitiba - PR: Editora Appris 2015, 187p.

SENA, Paulo de. A PEC Nº15/2015 E O NOVO FUNDEB. Nota Técnica. Consultoria do Legislativo da Área XV Educação, Cultura, Desporto, Ciência e Tecnologia. Disponível em http://www2.camara.leg.br/a-camara/documentos-e-pesquisa/estudos-e-notas-

tecnicas/areas-da-conle/tema 11/a-pec-no-15-2015-e-o-novo-fundeb-paulo-de-sena. Acesso em junho de 2018

SOUZA JR., Luiz de. FUNDEB: avanços, limites e perspectivas. Eccos: Revista Científica, São Paulo, v. 8, n. 2, p. 275-290, jul./dez. 2006. 